\title{
A África e a diplomacia para o desenvolvimento e paz: o caso de Cabo Verde*
}

\section{Africa and diplomacy for development and peace: the case of Cape Verde}

\section{Resumo}

Eesta nota diplomática, escrita pelo Embaixador da República de Cabo Verde no Brasil, por ocasião dos eventos comemorativos do Dia da África e dos 50 anos da União Africa, promovido pelo Centro Universitário de Brasília - UNICEUB, tem como objetivo trazer algumas reflexões sobre os avanços conquistados pelos países africanos nas últimas décadas e os principais desafios políticos, econômicos e sociais que assolam o continente nas primeiras décadas do século XXI. O texto dá uma especial ênfase ao processo de desenvolvimento do arquipélago de Cabo Verde.

Palavras-Chave: África. União Africana. Políticas de Desenvolvimento. República de Cabo Verde.

\begin{abstract}
This diplomatic note, written by the Ambassador of the Republic of Cape Verde in Brazil, on the occasion of the anniversary celebrations of Africa Day and the 50th anniversary of the African Union, aims to bring some reflections about the progress made by African countries in recent decades and to discuss political, economic and social issues that plague the continent in the early twenty-first century. The text gives special emphasis to the development of the archipelago of Cape Verde.
\end{abstract}

Keywords: Africa. African Union. Development Policy. Republic of Cape Verde.

\footnotetext{
* Artigo recebido em: 27/05/ 2013. Aprovado em: 18/06/2013. Este texto está escrito com as regras ortográficas da língua portuguesa vigentes na República de Cabo Verde

1 Embaixador da República de Cabo Verde no Brasil
} 


\section{Introdução}

Gostaria de agradecer, antes de mais, à Prof ${ }^{a}$ Renata Rosa, do Departamento das Relações Internacionais do UNICEUB o amável convite para participar neste evento, enquadrado nas comemorações do jubileu de ouro da fundação da Organização da Unidade Africana, hoje União Africana, a que o Centro Universitário de Brasília, em boa hora, se quis associar, partilhando com os presentes algumas reflexões, que inseri no texto cujo título é "A África e a Diplomacia para o Desenvolvimento e Paz - O caso de Cabo Verde".

Mas permitam-me, antes de entrar no âmago do tema escolhido, tecer ainda que breves considerações sobre a África que muitos órgãos de imprensa mundiais querem rotular e a realidade vem contestando os pregões.

Neste contexto, o Continente africano é, amiúde, tão somente confundido com guerras, fome, AIDS, analfabetismo, miséria. Tudo isso é, em parte, certo, mas a África não é apenas isso. O nosso Continente também produz riqueza, cultura, literatura, história, constrói, paulatinamente a paz, avança a passos firmes, rumo ao progresso e ao desenvolvimento.

Este mesmo Continente que, às vezes, se nos apresentam como um autêntico marasmo, donde nada de bom pode vir, é o mesmo que pariu civilizações requintadas como a do Egipto, Cartago mercantil ou figuras de proa, desde a mais alta antiguidade, como Santo Agostinho; é o mesmo que deu à luz quatro Prémios Nobel da Literatura (o nigeriano, Wole Soynka, os sul-africanos, Nadine Gordimer e John Maxwell Coetzee, o egípcio, Nagib Mahfuz), quatro Prémios Nobel da Paz, sendo três originários da África do Sul, designadamente, Desmond Tutu, em 1984, Nelson Mandela e Frederik de Klerk, em 1993 e a queniana, Wangari Maathai, em 2004. E por falar em laureados, porque não indicar, igualmente, os nomes dos escritores José Craveirinha de Moçambique, Pepetela de Angola e Arménio Vieira de Cabo Verde, todos eles Prémios Camões?

Do seio da África, também nasceram personalidades como o maliano Amadou Hampaté Bâ, o burkinabé Joseph Ki Zerbo e o senegalês Cheikh Anta Diop, que pertenceram àquela geração de africanos que, utilizando as ferramentas metodológicas das escolas europeias operaram uma ruptura epistemológica profunda nos paradigmas dominantes e construíram um discur- so que permitiu desconstruir a prosápia europeia sobre o Outro, que dominou as ciências históricas no período colonial; ou então o egípcio Butrus Butrus Gali e o ganês Koffi Anan, que estiveram durante largos anos à frente de uma poderosa Organização como a das Nações Unidas. Para além de brilhantes professores e pesquisadores que no continente mãe ou noutro, fazem progredir a ciência e o saber, a massa anónima dinâmica, as mulheres batalhadoras, comerciantes dinâmicos e criativos. Em suma, milhões de anónimos.Fazem parte plenamente deste milénio!

Do ponto de vista estritamente económico, o crescimento à volta dos $2,4 \%$ do PIB nos anos 90 deu lugar a um aumento à volta de $4 \%$ anuais entre 2000 e 2004, tendo ultrapassado os $4 \%$ em 2005, e sendo que um grupo superior a 27 países ultrapassou os 5\% em 2007. Angola foi em 2008 o segundo país com maior crescimento do mundo com mais 20\%, seguido da Mauritânia com 13\%. Entre os países africanos de língua portuguesa, apenas a Guiné-Bissau ficou abaixo dos $6 \%$ de crescimento em 2007. A média atual do crescimento africano é de $5 \%$ e estamos em plena crise econômica, que vem assolando todo o Mundo. No entanto, 1/4 dos países africanos tiveram, em 2012, um crescimento igual ou superior a 7\%. As projeções para 2013 e 2014 indicam um crescimento econômico regional de, respectivamente, $5,5 \%$ e $6 \%$. Quer dizer, de há uns dez anos a esta parte, o crescimento econômico africano tem-se revelado ser sustentável.

A proporção da África na produção econômica mundial cresceu $5,5 \%$, ou seja, mais do que qualquer membro da OCDE. A inflação média no Continente é de um dígito, e em mais de 30 países está abaixo dos 5\%.

O crescimento do IED com destino africano cresceu $200 \%$, entre 2000 e 2005 (saltando de 7 para 23 bilhões de dólares), enquanto a Ásia ficou com um crescimento de apenas $60 \%$. É claro que o ponto de partida da África é mais baixo, mas ainda assim os números são espetaculares e a tendência continua a ser de consolidação, tanto que, em 2012, o montante global do IDE, em África, atingiu a cifra de 54,5 bilhões de usd.

Por outro lado, muitos se admiram pelo facto de a bolsa de valores de Johannesburg ter uma capitalização superior à da Bovespa ou à da Bolsa de Xangai. Além disso, um fator determinante para atrair o financiamento externo tem sido a redução do peso da dívida, que par- 
cialmente foi perdoada e em outra grande parte foi eliminada: o maior devedor africano, a Nigéria, pagou toda a sua dívida.

$\mathrm{Na}$ área comercial as exportações africanas cresceram $25 \%$ em média nos últimos três anos, uma "performance" igual à da China, a ser comparada aos $14 \%$ do resto dos países do Sul.

A União Africana introduziu, pela primeira vez, princípios escrupulosos de respeito à ordem constitucional, aos direitos humanos e apela a uma avaliação de pares sobre a governança dos países.

Dito isso, passemos, então, a abordar o tema que nos proposemos tratar nesta pequena intervenção, cujo título anteriormente enunciámos.

\section{Em jeito de preâmbulo}

A maioria dos aqui presentes, não eram sequer nascidos à data da independência de Cabo Verde. Principalmente por essa razão, dificilmente poderão avaliar, com propriedade, as transformações que as ilhas cabo-verdianas sofreram nos últimos trinta e oito anos.

A desesperança, criada, desenvolvida e interiorizada pelo atavismo, provocado por uma conhecida história de seca e fome cíclicas, através da qual o nosso arquipélago se tornara tristemente célebre, ao logo de séculos, cedeu lugar à esperança e à crença mais íntima, face aos resultados conseguidos, a todos os níveis (falaremos disso mais adiante), fruto do labor de todos os cabo-verdianos e da ajuda internacional;

A descrença inicial nas nossas possibilidades, imposta por uma natureza ignara e inclemente, mas também inculcada através de uma mentalidade de subserviência, que o colonialismo, subtilmente, deixou que invadisse o nosso âmago, deu lugar à crença dos cabo-verdianos nas suas capacidades para superar todas as dificuldades, mesmo as impossíveis, como aquelas que poetas nacionalistas, a exemplo de Ovídio Martins, passaram a transmitir às novas gerações, com a imagem das cabras, que nos ensinaram a "comer pedras para não perecermos";

Recuperada a esperança, a crença, a própria auto estima e a autonomia de decisão, parte-se, então, para a aventura, empolgante, da construção de um Estado, reivindicada pela pré existência de uma Nação, fenómeno algo paradoxal, por ter acontecido num contexto histórico colonial, classificado, precisamente por isso, por certos cientistas sociais e políticos, como algo que, como toda a construção histórica, aconteceu de forma independente da vontade dos homens.

Foi a fina percepção desse facto, corporizada pela sagacidade dos dirigentes nacionalistas da época, designadamente Amílcar Cabral, antecedido já pelos nativistas da segunda metade do século XIX e primeira do século $\mathrm{XX}$, que explica a luta vitoriosa pela independência. Uma primeira vitória, conseguida, desde logo, contra um adversário melhor armado e bem equipado. Para além disso, a força das convicções, a ideia motriz do restabelecimento da dignidade perdida, por via da recuperação da História e da cultura usurpadas, logo da valorização da própria identidade, razão de ser última da independência almejada.

Conquistada a soberania nacional, eis que surge o primeiro grande embate/desafio: o da construção de um Estado, que muitos pensavam ser algo impossível, porque com os recursos disponíveis tal empresa se revelava, na aparência, inviável economicamente. Provou-se, no entanto, exactamente o contrário do propalado pelos profetas da desgraça: que o Cabo Verde independente não sobreviveria seis meses.

Efectivamente, a riqueza das ilhas de Cabo Verde, resumia-se, em 1975, ao seguinte: mais de $70 \%$ da população analfabeta; pobreza e miséria crónicas; 200 USD de PIB per capita; 10 médicos, 2 ginásios, pouco mais de duas dúzias de estabelecimentos de instrução primária; um tesouro público exaurido e tecnicamente falido; ausência quase total de recursos naturais exploráveis e de infra-estruturas, estradas, portos, aeroportos, saneamento básico; um povo indómito e corajoso, que se recusava vergar perante o peso da natureza ou da História, ingratas a vários títulos.

Foram estas as condições de arranque. E convenhamos que elas não eram nada auspiciosas. Por isso, utilizava, ainda há pouco, o termo "aventura", para qualificar o processo da construção do nosso Estado.

Passados que foram cerca de trinta e oito anos sobre o início da nova aventura cabo-verdiana, historicamente falando, a primeira foi o da ocupação humana do nosso espaço, para onde tiveram de ser transportadas todas as condições para permitir esse desiderato, são por demais evidentes os ganhos obtidos: 
a. a construção de novos portos e aeroportos;

b. aumento significativo da rede de estradas de penetração, calcetadas, numa primeira fase, agora asfaltadas, melhorando as condições dos transportes e das comunicações entre os diversas cidades e vilas das ilhas;

c. centenas de estabelecimentos de ensino, primário, atingindo, praticamente, todas as aldeias do país, onde praticamente $100 \%$ das crianças em idade escolar têm acesso ao sistema de ensino, obrigatório e gratuito até ao sexto ano de escolaridade;

d. cerca de uma dezena e meia de ginásios, para apenas falar de uma única ilha, a de Santiago;

e. escolas técnicas em diversas ilhas; institutos superiores de formação de professores do ensino secundário e do magistério primário; o nascimento de diversas Universidade privadas, nos últimos anos, e de há cinco a esta parte surgiu a primeira Universidade pública, a UniCV, graças à cooperação brasileira e portuguesa, que ajudaram na sua montagem e dimensionamento;

f. várias centenas de médicos e enfermeiros, que trabalham em diversos Hospitais Centrais, com diferentes valências;

g. hospitais regionais, centros e postos de saúde, espalhados um pouco por todo o país;

h. proliferação de clínicas privadas e consultórios médicos nos principais centro populacionais;

i. condições e qualidade de vida da população amplamente melhoradas, ainda que persistam ainda, naturalmente, bolsas de pobreza, em algumas ilhas mais do que noutras.

Do mesmo modo, uma enorme explosão se fez bibliotecas e museus, a defesa do património histórico nacional construído, a afirmação e o desenvolvimento de diversos aspetos da cultura cabo-verdiana, cimento da Nação, como a música, a dança e a literatura, com um enorme surto da editoração, em muitas vertentes da produção literária, nas artes, ganhando a expressão cultural de Cabo Verde alguma notoriedade internacional, sobretudo nos campos da música e da literatura.

Foram precisamente os índices de desenvolvimento humanos atingidos e o incremento significativo do $\mathrm{PIB}$, que empurram Cabo Verde para fora dos Países Menos Avançados (PMA). Apesar de tudo, o país continua a ser considerado, pelo próprio sistema das Nações Unidas, que decidiu a saída de Cabo Verde dos PMA, como dos mais vulneráveis do mundo, tais são as suas fraquezas e debilidades, económica e ambiental sobretudo.

Contrariando todos os prognósticos iniciais, Cabo Verde é, hoje, um país socialmente coeso, politicamente estável e maduro, constituindo um exemplo de Estado de Direito Democrático em África, onde as instituições funcionam normalmente, a alternância democrática é uma realidade, depois de uma transição política, considerada, também ela, pela comunidade internacional como exemplar, em que os direitos, liberdades e garantias estão perfeitamente delimitados e defendidos, constitucionalmente e por instituições de justiça independentes do poder político, caraterística essencial dos Estados democráticos modernos. Bem que se pode dizer, sem margem para dúvidas, que Cabo Verde justificou, amplamente, a sua independência!

Obviamente, o esforço consentido não foi pequeno. Nem os cabo-verdianos estiveram sozinhos neste empreendimento e nos resultados obtidos. Mas só se pode sentir justificado orgulho pelo que Cabo Verde conseguiu alcançar em todos estes anos de independência, com muitas apostas decididamente ganhas, tanto na área da saúde, como do ensino, além do relativo desenvolvimento económico, com o PIB per capita a atingir, atualmente, de mais de 3 mil USD, multiplicando-se, assim, por quinze os valores de 1975.

Pode-se ainda afirmar, sem receio de nos enganarmos muito, que o segredo daquilo que o país conseguiu atingir, ao longo deste tempo, deve-se, em grande medida, à política externa implementada por sucessivos Governos de Cabo Verde, que se têm mantido fiel a certos e 
determinados princípios basilares. Pela sua importância crucial na estratégia de desenvolvimento de Cabo Verde, falaremos, de seguida, sobre essa importante matéria.

\section{Diplomacia para o desenvolvimento e cons- trução da paz}

Falar da diplomacia cabo-verdiana nestes últimos 38 anos, empurra-nos, necessariamente, a ir beber à fonte da Luta de Libertação Nacional.

Assim, é preciso saber que o patriotismo e o nacionalismo de Amílcar Cabral se manifestaram, sobretudo, de uma forma que se pode considerar fundamental e importantíssima, marcando, em profundidade, todo o percurso da luta travada pelo PAIGC. Referimo-nos à não hipoteca ou alienação de princípios, particularmente no que dizia respeito à manutenção de um elevado grau de independência de pensamento e de ação, desde sempre defendido, com determinação, por Cabral e os seguidores. Neste quadro, os apoios e ajudas eram aceites quando não acompanhadas de imposição de condições políticas incompatíveis com esse princípio.

Por isso, para a concretização de tais princípios no domínio político, era necessário orientar-se por soluções adequadas. E, apreciando o ambiente internacional e a correlação de forças da época, a fórmula encontrada para conduzir a política externa, foi diversificar os contactos e alianças, de maneira a gerir a relativa e difícil autonomia e independência perante os aliados "naturais" e tradicionais, salvaguardando, com perseverança, a coerência no respeitante aos interesses políticos mais nobres.

Também, só o génio prospetivo de A. Cabral para antecipar não só as excelentes relações que viriam a ser entretecidas, ao longo dos tempos, entre Cabo Verde e Portugal, ao distinguir, de forma clarividente, o que era o regime colonial/fascista e o povo português, mas também concebendo a CONCP, organização directamente precursora dos Países Africanos de Língua Oficial Portuguesa (PALOP), lançando as sementes fecundas da futura Comunidade dos Países da Língua Portuguesa (CPLP).

Esta fórmula de sucesso foi implementada em Cabo Verde, desde a independência, conquistada a 5 de Julho de 1975. Opção que não foi isenta de consequências e exigências no desempenho da política externa do país, nos tempos subsequentes. É assim que se explica, também, a adesão ao Movimento dos Não Alinhados e ao Grupo dos 77.

Quem conheceu as difíceis condições de arranque, à data da independência, de um país pequeno e sem recursos para fazer face aos enormes desafios do processo de desenvolvimento, o mínimo que se pode dizer da escolha de Cabo Verde é que ela era tanto arrojada quanto corajosa. Uma aposta de alto risco que, em face dos resultados obtidos, não poderia deixar de ser alvo dos maiores encómios da comunidade internacional.

Desde logo, foram demonstradas ambição e crença nas capacidades de um povo, habituado a enormes desafios e a vencer todas as calamidades.

Contrariando os mais cépticos, Cabo Verde cresceu e avançou. E as vitórias alcançadas, no plano externo e de desenvolvimento económico, constituem justo orgulho de todo o seu povo, que se armou com o escudo da Nação para mostrar que nada é impossível, quando existe querer, vontade, perseverança e, sobretudo, engajamento em torno de um grande desígnio nacional, que continua a ser o desenvolvimento e o bem-estar de todos os caboverdianos, onde quer que se encontrem.

Mas para além da crença e autoconfiança, houve que mobilizar amigos, parceiros para a causa. E a diplomacia cabo-verdiana não se poupou a esforços nesse sentido. E desde início, para demonstrar a seriedade de propósitos começou-se a dar sinais claros, à comunidade internacional, de que a postura de Cabo Verde iria ser salutar e de abertura, mas coerente com os princípios norteares da acção externa cabo-verdiana, em defesa dos interesses nacionais mais lídimos.

A diferença com determinadas práticas, infelizmente bastante comuns na época, começava a ser marcada, de imediato, com a forma como a ajuda prodigalizada pela comunidade internacional foi utilizada pelos governos de Cabo Verde para a geração de recursos para o desenvolvimento, através da sua comercialização, e não para a distribuição gratuita às populações, o que, como se sabe, só contribuiria para manter a dependência externa do país. É assim que surgem os chamados Fundos de Contrapartida, que passariam a constituir uma exigência dos doadores internacionais a todos os beneficiários da Ajuda Pública ao Desenvolvimento (APD). 
Foi, deste modo, crescendo a credibilidade e prestígio internacional do país, hoje considerados como um recurso estratégico em matéria de capitalização das nossas relações externas, procurando, com isso, obter cada vez mais meios económicos para o financiamento do seu desenvolvimento.

Mas os créditos não ficaram por aí. O país quis ser útil no concerto das Nações, quando se tratava da busca de soluções pacíficas para os litígios, algumas vezes sangrentos, entre os Estados. E, nesse quadro, o papel facilitador de um pequeno país como Cabo Verde na resolução do conflito na África Austral, como o conflito angolano, envolvendo a África do Sul, tropas cubanas em solo de Angola, tem o seu quê de importância e valor.

Fazendo parte, desde os finais dos anos 80, do Comité Ad Hoc da Organização da Unidade Africana (OUA) para a África Austral, já antes, a ilha do Sal fora cenário de consultas secretas, tripartidas, entre a África do Sul, Angola e Cuba, visando a retirada cubana e sul-africana de Angola e a solução desse mortífero conflito.

E essa ação de bons ofícios de Cabo Verde acontecia na sequência de uma das mais brilhantes vitórias diplomáticas de Cabo Verde na cena internacional.

Efetivamente, no contexto da luta anti-apartheid, o país esteve sob a ameaça de sanções por parte da OUA, por causa da passagem dos aviões da South Africa Airlines (SAA) no aeroporto internacional da ilha do Sal.

A argumentação político-diplomática cabo-verdiana não só conseguiu evitar as sanções como contribuiu para aumentar o prestígio do país no seio da organização pan-africana, o que levou, por proposta de Angola, à nossa integração no referido Comité $A d H o c$.

De referir, ainda, o fato de Cabo Verde ter dado uma grande contribuição para as negociações entre representantes do Governo minoritário branco da África do Sul e a SWAPO visando a independência da Namíbia, tendo os primeiros encontros diretos entre as duas partes tido lugar na cidade do Mindelo, na ilha de S. Vicente.

É, também, nos anos 80 que Cabo Verde assume a Presidência, durante quase uma década, da Comissão Preparatória para a Autoridade Internacional dos Fundos Marinhos, no âmbito da Conferência das Nações Unidas para o Direito do Mar.
De igual modo, durante o biénio 1992/93, Cabo Verde fez parte do Conselho de Segurança das Nações Unidas, como membro não permanente, cargo para que foi eleito brilhantemente, batendo a poderosa candidatura de um país com a dimensão e importância da Nigéria. A essa vitória mais, da diplomacia cabo-verdiana, não está, certamente, alheio o prestígio e credibilidade internacionais, que se foi angariando ao longo de todos esses anos.

Tenha-se presente que, durante esse mandato, cuja presidência esteve a nosso cargo, em Julho de 1992, se discutiram importantes e candentes questões internacionais da altura, como a Líbia, a Somália, a Bósnia Herzegovina, Angola e África do Sul, entre outras, e teve lugar a única Cimeira do Conselho de Segurança, realizada até ao presente momento.

E eis que, na atualidade, novos e formidáveis desafios pespontam no horizonte da diplomacia cabo-verdiana, num mundo ainda mais competitivo, globalizado, em que o mar das relações internacionais se encontra cada vez mais encapelado.

Trata-se, agora, de responder às exigências da mudança de estatuto do processo do nosso desenvolvimento, passando Cabo Verde de País Menos Avançado (PMA) a País de Desenvolvimento Médio (PDM).

Não serão, certamente, poucos os obstáculos que teremos de transpor. Mas o povo cabo-verdiano, como no passado, saberá estar à altura das responsabilidades cometidas. E não estaremos sós nesse trajeto, como nunca estivemos.

Por alguma razão Cabo Verde foi, tem sido e continuará a ser, no plano externo, um país de consensos. Diplomaticamente falando, importa negociar, convenientemente, a "transição suave" no seio das Nações Unidas, tanto mais que, nessa questão, não existem muitas experiências onde ir beber. O único caso, que se conhece, em termos internacionais, de graduação de um país de uma para outra etapa de classificação em matéria de desenvolvimento, é o de Botswana. Só que este último país dispõe de apreciáveis recursos minerais como, por exemplo, os diamantes. E recursos, seja de que tipo for, é coisa de que Cabo Verde carece sobremaneira.

Não é crível que Cabo Verde, nestas circunstâncias, venha a ser vítima do seu próprio sucesso, quer di- 
zer, possa ser penalizado por ter sabido gerir, convenientemente, a ajuda internacional colocada à sua disposição. Porque, se é certo que o país superou dois dos três critérios, que o classificavam como PMA, como sejam o PIB per capita e o índice do desenvolvimento humano, não é menos verdade, que o terceiro critério, o do índice de vulnerabilidade económica e ambiental, está muito longe de ser superado, continuando Cabo Verde a ser classificado, pelo próprio sistema das Nações Unidas, como um dos países mais vulneráveis do mundo.

Mantém-se, porém, firme a nossa vontade de enfrentar e superar os difíceis obstáculos na corrida rumo ao desenvolvimento sustentado deste país que tanto amamos.

A integração de Cabo Verde no programa Millenium Challenge Account (MCA) dos Estados Unidos e o facto de o respectivo compacto ter sido negociado de forma rápida, e sua assinatura ter já acontecido desde Julho de 2005, ano do trigésimo aniversário da independência, foi já de si um sinal claro da determinação da diplomacia cabo-verdiana em ultrapassar todas as dificuldades da sua difícil mas orgulhosa caminhada como Estado livre e soberano. E Cabo Verde foi, novamente, classificado para um próximo Programa deste importante instrumento ajuda norte-americano a países em vias de desenvolvimento. E a nossa classificação obedeceu a critérios de ilegibilidade bem mais exigentes do que os anteriores, pois que com o estatuto de país de desenvolvimento médio e não mais como país menos avançado. Aliás, a nossa experiência na aplicação dos recursos colocados à nossa disposião no âmbito deste importante programa, começa a servir de modelo a outros países africanos irmãos, como é o caso do Gana.

Por alguma razão, o $\mathrm{BAD}$ apresentou, recentemente, Cabo Verde, na sua última reunião em Xangai, na China, que se realizou há pouco tempo, como um caso de sucesso em África, apesar dos problemas e dificuldades ainda subsistentes, como uma elevada taxa de desemprego, fixada em cerca de $24 \%$, a pobreza que afecta $37 \%$ da população, a dependência externa em matéria de bens alimentares e sendo que $20 \%$ do seu PIB resulta da remessa dos emigrantes.

Tenha-se, igualmente, em linha de mira, a nossa estratégica diplomática para a obtenção de uma Parceria Especial com a União Europeia, que ultrapassem os estritos marcos dos Acordos de Cotounou, ligando os paí- ses ACP à U.E. por laços particulares de cooperação, mas cujos contornos ainda não se encontram perfeitamente delimitados, porque estamos perante uma proposta, em construção, na discussão da qual o pragmatismo e a vontade política devem prevalecer, tratando-se de algo que interessa às duas partes em presença, no mundo da globalização e onde a segurança é, cada vez mais, uma exigência do nosso tempo e do futuro da Humanidade.

Além do mais, é preciso considerar, que o correspondente a $45 \%$ da população actual residente em Cabo Verde (cerca de 480 mil habitantes) reside na Europa e este é um elemento não despiciendo, a que importa conferir o seu justo valor.

Trata-se, todavia, de um projeto a longo prazo, uma autêntica corrida de fundo, que exige paciência, e perseverança, considerando os objetivos propostos, ao qual se devem agregar outras âncoras de desenvolvimento, previamente identificadas, seja em África (CEDEAO, Angola, África do Sul), América Latina (Brasil) ou América do Norte (Estados Unidos da América), país onde existe uma expressiva comunidade imigrada de origem cabo-verdiana, considerado, não apenas por isso, como estratégico para o desenvolvimento de Cabo Verde, tendo em linha de conta, sobretudo, aspetos de fundo relacionados com a segurança do país e de uma zona, a África Ocidental, que vem ganhando estatuto de região de importância geo-económica mundial, dada as suas enormes potencialidades em recursos energéticos fósseis. Importância tanto maior, quanto a instabilidade da região do Médio Oriente vai em crescendo, perante o agravamento da situação no Iraque, a persistência do conflito israelo-palestiniano, sem solução à vista, a que se agrega, agora, o Irão com o seu projeto nuclear, rejeitado liminarmente pela comunidade internacional, para só citar os casos mais emblemáticos e mediáticos.

Importaria, ainda, fazer uma breve referência às relações entre a África e o Brasil.

A chegada ao poder do Presidente Lula representou uma nova etapa nas relações com a África. Desde o início, dois objetivos estratégicos do Presidente - o reconhecimento da questão racial no Brasil e uma política externa privilegiando uma parceria estratégica com o Sul - tiveram um enorme impacto no Continente.

As sucessivas visitas do Presidente a mais de vinte países africanos, Cabo Verde, por exemplo, recebeu Lula 
da Silva por duas vezes; as tomadas de posição em fóruns internacionais; a criação de fundos de ajuda inovadores como o UNITAID; a importância dada à CPLP, a defesa do interesse comercial dos mais pobres na OMC, a política de aproximação cultural com a África e a I Cúpula dos Chefes de Estado e de Governo da África e América do Sul, realizada em Abuja, Nigéria, em Novembro de 2006, foram elementos importantes nas esferas de decisão do Continente. Depois disso, no quadro da ASA, tivemos mais duas Cúpulas, uma na Venezuela e outra na Guiné Equatorial, esta última muito recentemente. A iniciativa de acolher o II Encontro de Intelectuais Africanos e a Diáspora em Salvador da Bahia, em Julho 2006, foi mais uma prova desse interesse peculiar do Brasil.

No mesmo ano, teve lugar a I Cúpula do IBAS, com a aprovação de um plano de ação ambicioso. A diplomacia brasileira abriu mais de 15 novos postos diplomáticos no Continente. Empresas como a Petrobras, Companhia do Vale, a Odebrecht, Camargo Correa, Andrade e Gutierres, entre outras, aumentaram sua presença no Continente. O comércio externo com a África cresceu $26 \%$ por ano e $225 \%$ para os países africanos de língua portuguesa, desde 2004. O saldo positivo para o Brasil é da ordem dos 640 milhões de dólares. De todo o modo e de forma geral, entre 2005 e Outubro de 2006, o comércio entre o Brasil e a África mais do que duplicou, passando de 5 bilhões para 12,8 bilhões e atualmente é de cerca de 20 bilhões de usd, ou seja quintuplicou. E se considerarmos que, num cenário populacional mundial de 7 bilhões de habitantes, a África contribui com mais 1 bilhão de seres humanos, $16 \%$ da população mundial, logo veremos se tratar de um mercado consumidor que ninguém vai querer negligenciar. Aliás, a África, no seu conjunto, já é o terceiro parceiro comercial do Brasil.

\section{A cultura africana no mundo globalizado}

Vivemos sob o signo da promoção da cultura africana num mundo em processo de intensa e rápida globalização. Precisamente por isso, permitam-me, ainda, partilhar convosco, de forma muito rápida, algumas considerações acerca desse assunto, no contexto de jovens Estados africanos como Cabo Verde.

Um dos maiores problemas culturais dos países de origem colonial é o questionamento da sua identidade, sobretudo no mundo de hoje, em que a globalização torna particularmente difícil a sustentação de uma cultura própria face às culturas hegemónicas que, através dos audiovisuais e não só, nos desafiam permanentemente.

De fato, como algures já li, e faz todo o sentido, a independência política, sobretudo de países jovens, como é o caso de Cabo Verde, não é um fato definitivo. As independências ganham-se e perdem-se. A prova do seu enraizamento é o tempo. Uma independência recente é sempre ameaçada. Mesmo que permaneça como fato político, pode extinguir-se como fato cultural.

No mundo de hoje já não há colónias, é verdade. Mas o colonialismo cultural e económico pode contribuir, poderosamente, para fazer esvaziar a independência do seu conteúdo essencial. Assim, deve ser natural que um país que lutou com tanto empenho pela sua independência nacional, lute também com a mesma determinação pela consciência cultural da sua identidade.

Entre as diversas componentes da consciência de identidade, a história coletiva do povo é, sem dúvida, a mais importante. Mas essa questão pode revelar-se de uma enorme fragilidade, se não for convenientemente interiorizada e repetida às sucessivas gerações, porque numa terra, como Cabo Verde, onde mais de $50 \%$ da população tem cerca de 19 ou 20 anos de idade, essa memória corre o risco real e efetivo de esvasiar-se rapidamente. Por todas essas e outras mais razões não menos ponderosas, o ensino sistematizado da história do povo das nossas ilhas, em todas as escolas, se revela crucial para o futuro identitário do país e para a formação da consciência cívica da sua população. E isso é, igualmente, válido para a generalidade dos países africanos de expressão oficial portuguesa.

Praticamente trinta e oito anos deslizaram na História. Pouco tempo na caminhada dos anais. Para nós os que presenciámos o hastear das bandeiras vemos, agora, os nossos filhos e netos no limiar da idade adulta prestes a integrarem as fileiras da construção permanente. Alguns, de entre tantos aqueles que nestes bancos de Faculdades e Universidades brasileiras se têm formado, batalham já pelo presente, ainda na companhia dos mais velhos, em estafeta rumo ao amanhã.

As futuras páginas serão já dos mais jovens, que devem continuar a manter a crença inabálável, e com fundadas razões, no porvir da sua Nação. 
Que a África possa ser todo o ano, um só dia entre muitos outros em dignidade e equilíbrio, em razão de ser Homem de corpo e parte inteiros.

Brasília, 27 de Maio de 2013. 


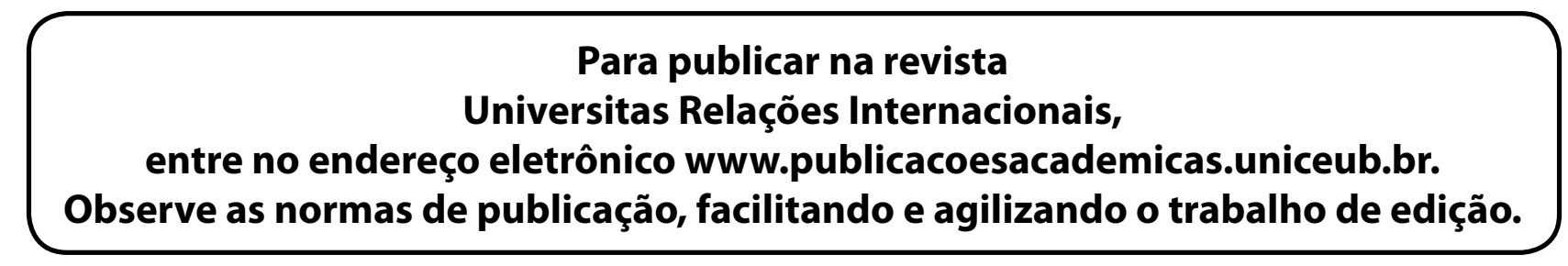

